\title{
Synthesis of Side Chain Liquid Crystal-Coil Diblock Copolymers with $p$-Methoxyazobenzene Side Groups by Atom-Transfer Radical Polymerization
}

\author{
Xiaohua HE, ${ }^{\dagger}$ Hailiang ZHANG, and Xiayu WANG \\ Department of Polymer Science and Engineering, College of Chemistry, \\ Xiangtan University, Xiangtan 411105, China
}

(Received January 15, 2002; Accepted May 24, 2002)

\begin{abstract}
The synthesis of two series of liquid crystal-coil (LC-coil) diblock copolymers with narrow molecular weight distributions was achieved by atom-transfer radical polymerization (ATRP), which was designed to have LC conformation of poly[6-(4-Methoxy-4' -oxy-azobenzene) hexyl methacrylate] and coil-conformation of poly(ethylene oxide) (PEO) $\left(M_{\mathrm{n}}=5000\right.$ or 2000) segment. The LC block in every series was prepared with a wide rang of molecular weights from $3.5 \times 10^{3}$ to $1.7 \times 10^{4}$. The copolymers were characterized by proton nuclear magnetic resonance $\left({ }^{1} \mathrm{H} \mathrm{NMR}\right)$, Fourier Transform Infrared (FT-IR) spectra, gel permeation chromatograph (GPC), differential scanning calorimetry (DSC) and polarized optical microscope (POM). The block polymers exhibited a smectic and nematic mesophase. The phase transition temperatures of the smectic and nematic phase increased and the crystallization temperature of PEO decreased with increasing molecular weight of the LC block.

KEY WORDS Atom-Transfer Radical Polymerization (ATRP) / Diblock Copolymer / Liquid Crystal / Poly(ethylene oxide) (PEO) /
\end{abstract}

Block and graft copolymers composed of incompatible polymer segments can in general self-assemble into a variety of supramolecular structures in the solid state or in a selective solvent. Especially block copolymers with a narrow molecular weight distribution of their components are expected and known to display very regular long rang ordered structures, which present new materials with superior properties. Compared with conventional coil-coil diblock copolymers, the block copolymers containing liquid crystal (LC) block may form multiple morphological structures because of LC block possessing multiple ordering processes. ${ }^{1} \mathrm{By}$ definition, LC block copolymers contain at least one LC segment and may have structures including rod-coil, ${ }^{2-6}$ side group LC-coil ${ }^{7-11}$ and other block combinations. ${ }^{12}$

In recent years, the side group LC-coil (SGLC-coil) block copolymers have drawn great attention. Several research groups have reported the synthesis and characterization of the side group LC-coil these block copolymers. They employed many types of living polymerization methods to synthesize these block copolymers including anionic, ${ }^{7}$ ring-opening metathesis, ${ }^{8}$ and cationic ${ }^{9}$ living polymerization, and they reported that these block copolymers displayed liquid crystalline behavior similar to homopolymers and formed a microphase separation structure. Besides living polymerization methods, polymer-analogous reactions ${ }^{10}$ have also been used, where one block with functional groups could attach to the reactive mesogen. The procedure of this method is easier than that of the living polymerization but the conversion may be low.

In this paper, we synthesized the side group LCcoil block copolymer by atom-transfer radical polymerization, which has azobenzene group as the mesogenic moiety and the poly(ethylene oxide) as the coil segment. The azobenzene is a typical mesogen with special optical properties. The poly(ethylene oxide) (PEO) possesses many excellent properties, such as hydrophilic, nonionic, crystalline, and which can complex monovalent metallic cations to produce new conductive materials. ${ }^{13}$ The diblock copolymers were designated here "PEO5000 (or 2000)-b-PMMAZOn" ( $n=10-50$, the theoretical degree of polymerization of LC block). The structures and thermotropic phase behavior of the diblock copolymers have been characterized.

\section{EXPERIMENTAL}

\section{Materials}

4-(Dimethylamino)-pyridine (DMAP) (Acros, 99\%), $\mathrm{CuBr}$ (Adrich, 99.999\%), 1,6-dibromohexane (Acros, 98\%), 2.2'-dipyridine (dipy) (Acros, 99\%), and 2bromo-2-methylpropionylbromide (Acros, 98\%) were used without further purification. Chlorobenzene $\left(\mathrm{C}_{6} \mathrm{H}_{6} \mathrm{Cl}\right)$ (Acros, 99\%) was purified by washing with concentrated sulfuric acid to remove residual thiophenes, followed by washing twice with water, once with $5 \%$ sodium carbonate solution, and again with wa-

${ }^{\dagger}$ To whom correspondence should be addressed (hxhencn@yahoo.com, xiaohuahe@163.com). 
ter before being dried with anhydrous calcium chloride and distilled. Triethylamine (TEA) (Shanghai Chemical Reagents Co., A. R. grade) was refluxed with $\mathrm{KOH}$ and distilled. Methylene dichloride $\left(\mathrm{CH}_{2} \mathrm{Cl}_{2}\right)$ (Shanghai Chemical Reagents Co., A. R. grade) was shaken with portions of concentrated sulfuric acid until the acid layer remained colorless, then washed with water, aqueous $5 \% \mathrm{NaHCO}_{3}$ and with water again, and finally distilled from $\mathrm{CaH}_{2}$. Poly(ethylene oxide) monomethyl ether (PEO) $\left(M_{\mathrm{n}}=5000\right.$ and 2000) (Alfa Aesar) was fractionated. 6-(4-methoxy-azobenzene-4'-oxy) hexyl methacrylate (MMAZO) was prepared using the procedure described by Craig and Imrie. ${ }^{14}$ All other reagents were used as received.

\section{Preparation of PEO-Br Macro-initiators}

The synthesis of PEO- $b$-PMMAZO was shown in Scheme 1.

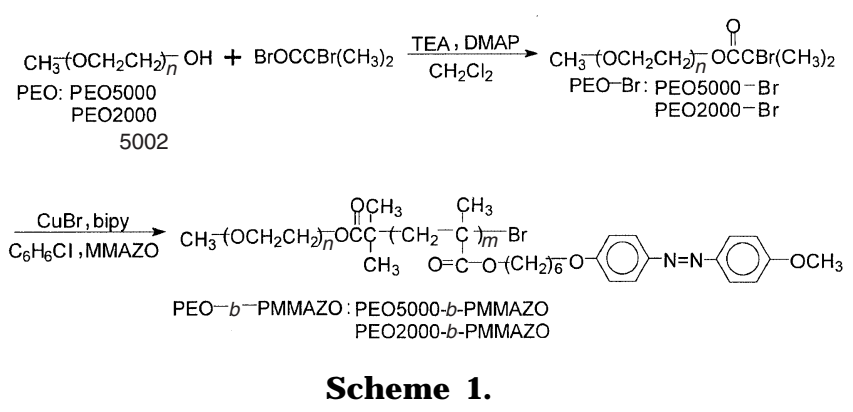

The macro-initiators were prepared according to the method described by Jankova and coworkers: ${ }^{15}$ a certain amount of DMAP $(0.92 \mathrm{~g}, 7.5 \mathrm{mmol})$ in $10 \mathrm{~mL}$ of dry methylene chloride was mixed with TEA $(0.7 \mathrm{~mL}, 5 \mathrm{mmol})$. The solution was transferred into a $250 \mathrm{~mL}$ three-neck round-bottom flask equipped with condenser, dropping funnel, gas inlet/outlet, and a magnetic stirrer. After cooling to $0^{\circ} \mathrm{C}, 2$-bromo-2methylpropionyl bromide $(2.88 \mathrm{~g}, 12.5 \mathrm{mmol})$ in $10 \mathrm{~mL}$ $\mathrm{CH}_{2} \mathrm{Cl}_{2}$ was added. PEO $5000(25.0 \mathrm{~g}, 5.0 \mathrm{mmol})$ or PEO $2000(10 \mathrm{~g}, 5.0 \mathrm{mmol})$ in dry $\mathrm{CH}_{2} \mathrm{Cl}_{2}$ was added dropwise to the formed yellow dispersion in one hour under nitrogen, then the temperature was allowed to rise to room temperature. The reaction was continued under stirring for $24 \mathrm{~h}$. The solution was removed in rotary evaporator. The crude PEO macro-initiator was dissolved in $50 \mathrm{~mL}$ benzene, filtered and precipitated in cold ethyl ether. The crude PEO-Br macro-initiator was recrystallized in absolute ethanol two times and dried in vacuum.

\section{Synthesis of PEO-block-PMMAZO}

PEO- $b$-PMMAZO diblock copolymers were synthesized by solution polymerization in chlorobenzene. Thus, in a typical solution polymerization, a polymerization tube was charged with PEO5000 macro-initiator $(0.500 \mathrm{~g} \quad 0.01 \mathrm{mmol}), \quad$ MMAZO $(0.340 \mathrm{~g} 0.10 \mathrm{mmol}), \mathrm{CuBr}(1.430 \mathrm{mg} 0.01 \mathrm{mmol})$, bipy $(4.686 \mathrm{mg} 0.03 \mathrm{mmol})$ and chlorobenzene $(4.500 \mathrm{~g})$, and then after degassing with three freeze-thaw cycles, the tube was sealed off under vacuum. The reaction was carried out at $75^{\circ} \mathrm{C}$ for $10 \mathrm{~h}$, and was then cooled to room temperature. The sample was further diluted with tetrahydrofuran (THF), removed copper salts through a plugged column of neutral aluminum oxide and precipitated in a large volume of cold methanol. The sample was purified by reprecipitating three times from THF to methanol and dried in a vacuum oven overnight at room temperature. The conversion of polymerization was determined gravimetrically.

\section{Chartaterization}

Molecular weights $M_{\mathrm{n}}$ and polydispersity $M_{\mathrm{w}} / M_{\mathrm{n}}$ were measured on a gel permeation chromatograph (Waters 150C) equipped with three Waters Styragel columns $\left(10^{3}, 10^{4}\right.$, and $\left.10^{5} \AA\right)$ using THF as an eluent at $35^{\circ} \mathrm{C}$. The column system was calibrated by a set of mono-dispersed standard polystyrenes. ${ }^{1} \mathrm{H}$ NMR spectra were obtained on a 200 Varian NMR instrument using $\mathrm{CDCl}_{3}$ as solvent, tetramethyl silane as the internal standard. The block copolymers composition were determined by either the $M_{\mathrm{n}}$ or the ratio of the ${ }^{1} \mathrm{H}$ NMR signal intensity of the phenyl peak region (6.7$7.9 \mathrm{ppm}$ ) to that of the PEO region (3.4-3.7 ppm). Thermograms were obtained using a Perkin-Elmer DSC-7 instrument. Pure indium was used as a reference material to calibrate both the temperature scale and the melting enthalpy before the sample was tested. Samples with a typical mass of $5.0 \pm 0.1 \mathrm{mg}$ were encapsulated in sealed aluminum pans and were heated at $10^{\circ} \mathrm{C} \mathrm{min}^{-1}$ heating rate from $-20^{\circ} \mathrm{C}$ to $160^{\circ} \mathrm{C}$ under nitrogen for the first scan, immediately cooled at $10^{\circ} \mathrm{C}$ $\mathrm{min}^{-1}$ cooling rate to $-20^{\circ} \mathrm{C}$ and then heated at $10^{\circ} \mathrm{C}$ $\mathrm{min}^{-1}$ heating rate from $-20^{\circ} \mathrm{C}$ to $160^{\circ} \mathrm{C}$ for the second scan. Polarized optical microscope (POM) observation was performed on a Leica DMLP microscope with a Leitz 350 hot stage. Infrared (FT-IR) spectra were recorded on Bomem MB100 Fourier Transform Infrared (FT-IR) Spectrometer.

\section{RESULTS AND DISCUSSION}

\section{Preparation of Macro-initiator PEO-Br and Block Copolymers}

The PEO-Br macro-initiators were synthesized by reacting PEO with acid bromide (Scheme 1) and carried out at $0^{\circ} \mathrm{C}$ in the presence of TEA and DMAP. Figure 1 shows the FT-IR spectra of the macro-initiators and part 


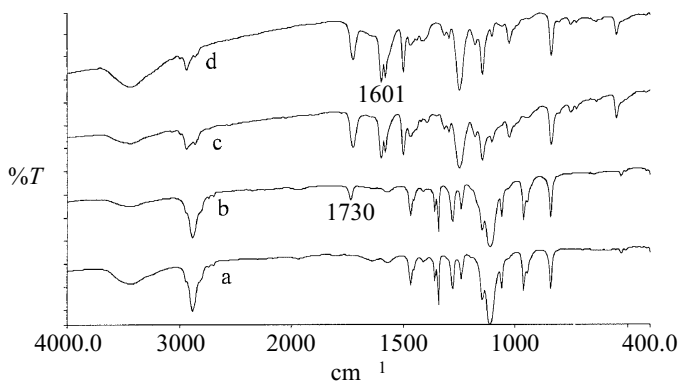

Figure 1. FT-IR spectra: ${ }^{\mathrm{a}} \mathrm{PEO} 5000, \quad{ }^{\mathrm{b}} \mathrm{PEO} 5000-\mathrm{Br}$, ${ }^{\mathrm{c}}$ PEO5000- $b$-PMMAZO30, ${ }^{\mathrm{P}} \mathrm{PMMAZO}$.

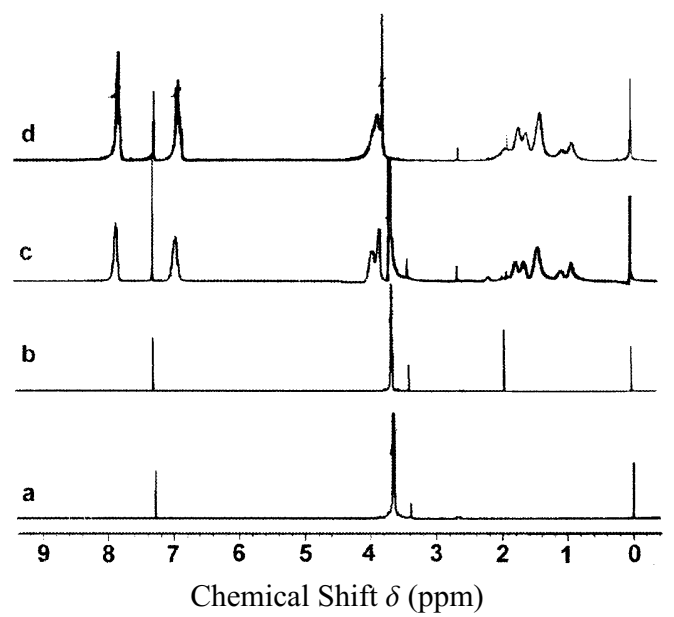

Figure 2. ${ }^{1} \mathrm{H}$ NMR spectra: ${ }^{\mathrm{a}} \mathrm{PEO} 5000, \quad{ }^{\mathrm{b}} \mathrm{PEO} 5000-\mathrm{Br}$, ${ }^{\mathrm{c}} \mathrm{PEO} 5000-b$-PMMAZO30, ${ }^{\mathrm{d}} \mathrm{PMMAZO}$.

Table I. Molecular weight characteristics of PEO and PEO-Br macroinitiators

\begin{tabular}{lccc}
\hline & & \multicolumn{2}{c}{ GPC results } \\
\cline { 3 - 4 } Polymer & $M_{\mathrm{n}}^{\text {theory }}$ & $M_{\mathrm{n}}$ & $M_{\mathrm{w}} / M_{\mathrm{n}}$ \\
\hline PEO2000 & 2000 & 2870 & 1.03 \\
PEO2000-Br & 2149 & 2930 & 1.03 \\
PEO5000 & 5000 & 7500 & 1.03 \\
PEO5000-Br & 5149 & 7650 & 1.03 \\
\hline
\end{tabular}

of the block copolymers for PEO 5000 system. The characteristic absorb peak of ester group at $1730 \mathrm{~cm}^{-1}$ is observed on the FT-IR spectra for the PEO-Br macroinitiators. The substitution of the hydroxyl groups was proved by ${ }^{1} \mathrm{H}$ NMR spectroscopy. A new signal appears at $1.90 \mathrm{ppm}$ on the ${ }^{1} \mathrm{H}$ NMR spectrum (Figure 2). By GPC analysis, it was found that the synthesis of the PEO-Br macro-intitiators involved no molecular weight reduction since narrow symmetrical signals were observed at essentially the same position as the starting PEO. The data are given in Table I. In order to make the hydroxyl groups completely substituted, the ratio of the amount of 2-bromo-2-methylpropionyl-bromide to that of PEO was 2.5 times.

The telechelic PEO-Br macro-initiators were used to initiate monomer MMAZO in the Chlorobenzene solution for formation of PEO- $b$-PMMAZO by ATRP.

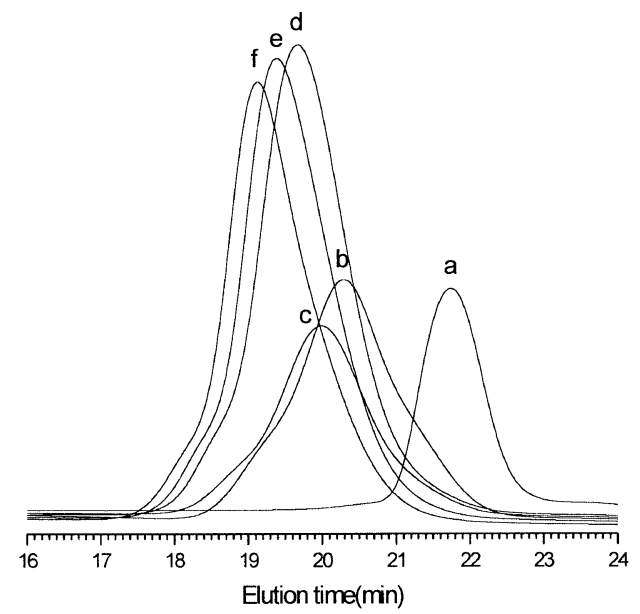

Figure 3. GPC traces: ${ }^{\mathrm{a}} \mathrm{PEO} 5000,{ }^{\mathrm{b}} \mathrm{PEO} 5000-b$-PMMAZO10, 'PEO5000- $b$-PMMAZO20, $\quad$ 'PEO5000- $b$-PMMAZO30, ${ }^{\mathrm{e}} \mathrm{PEO} 5000-b$-PMMAZO40, ${ }^{\mathrm{f}} \mathrm{PEO}$ 5000- $b$-PMMAZO50.

GPC analysis of the purified products showed no signal of residual PEO-Br macro-initiator and monomer MMAZO in the elution traces. Figure 2 depicts the ${ }^{1} \mathrm{H}$ NMR spectra. Figure 3 shows the GPC traces of the series of PEO5000- $b$-PMMAZO. We can observe the characteristic absorb peak of phenyl group at $1601 \mathrm{~cm}^{-1}$ (Figure 1) and a characteristic resonance originating from phenyl moieties at both 7.9 and $6.7 \mathrm{ppm}$ in the ${ }^{1} \mathrm{H}$ NMR spectrum of the diblock copolymer (Figure 2). At the same time, by GPC analysis (Figure 3), it was found that the molecular weight of the copolymer increased. Therefore, we may have the conclusion that PEO-Br can initiate monomer MMAZO and produce a diblock copolymer by ATRP. According to the area of integrating the phenyl and aliphatic peak regions in the ${ }^{1} \mathrm{H}$ NMR spectra of the two series of diblock copolymers, the contents of PMMAZO were from $35.8 \%$ to $65.2 \%$ for the series of PEO5000- $b$-PMMAZO and from $54.6 \%$ to $74.3 \%$ for the series of PEO2000- $b$-PMMAZO. By the examination of GPC, it was obtained that the contents of PMMAZO in the series of PEO5000- $b$-PMMAZO changed from $45.8 \%$ to $66.4 \%$, the contents of PMMAZO in the series of PEO2000- $b$-PMMAZO changed from $61.1 \%$ to $83.8 \%$. The diblock polymers PEO$b$-PMMAZO with narrow polydispersity can be synthesized by ATRP and the values of polydispersity of these block copolymers were around 1.10 (Table II). From the review of living polymerization methods ${ }^{6-12}$ employed to synthesize well-define SGLC-coil block copolymers, we first synthesized side chain liquid crystal-coil diblock copolymers with azobenzene side groups by ATRP.

\section{Thermotropic Phase Behavior}

The phase behaviors of PEO- $b$-PMMAZO were 
Table II. Characterization and thermal transitions of polymers

\begin{tabular}{|c|c|c|c|c|c|c|c|}
\hline \multirow[t]{3}{*}{ Polymer } & \multicolumn{2}{|c|}{ Yield $M_{\mathrm{n}}$} & $M_{\mathrm{w}} / M_{\mathrm{i}}$ & PM & $\begin{array}{l}\mathrm{O} \text { cont } \\
\mathrm{MMAZ} \\
\end{array}$ & \multicolumn{2}{|c|}{ Phase transitions $\left({ }^{\circ} \mathrm{C}\right)$ and corresponding enthalpy changes $\left(\mathrm{J} \mathrm{g}^{-1}\right)^{\mathrm{a}}$} \\
\hline & $\%$ & $\times 10^{-3}$ & & & & & \\
\hline & & & & NMR & GPC & Second heating & first cooling \\
\hline PEO5000 & - & 7.65 & 1.03 & - & - & K 59.0(194.7) I & I $40.3(-193.5) \mathrm{K}$ \\
\hline PEO5000- $b$-PMMAZO10 & 67 & 13.9 & 1.12 & 35.8 & 45.8 & K 54.6(83.0) g 67.9 S 81.4(0.5) I & I $78.4(-0.44)$ S $31.1(-80.6) \mathrm{K}$ \\
\hline PEO5000- $b$-PMMAZO20 & 65 & 16.2 & 1.13 & 52.2 & 53.6 & $\begin{array}{l}\text { K } 49.5(53.2) \text { g } 73.3 \text { S } 87.1(1.0) \\
\text { N } 110.9(1.2) \mathrm{I}\end{array}$ & $\begin{array}{l}\text { I } 108.2(-0.7) \mathrm{N} 84.0(-1.0) \\
\text { S } 28.1(-52.4) \mathrm{K}\end{array}$ \\
\hline PEO5000- $b$-PMMAZO30 & 72 & 18.1 & 1.15 & 56.4 & 58.5 & $\begin{array}{l}\text { K 46.5(40.8) g } 76.2 \text { S } 89.4(1.2) \\
\text { N } 117.0(0.7) \mathrm{I}\end{array}$ & $\begin{array}{l}\text { I } 114.4(-0.83) \mathrm{N} 86.0(-1.3) \\
\text { S } 26.3(-40.4) \mathrm{K}\end{array}$ \\
\hline PEO5000- $b$-PMMAZO40 & 68 & 20.0 & 1.14 & 64.1 & 62.5 & $\begin{array}{l}\text { K } 43.4(27.4) \text { g } 73.2 \text { S } 91.8(1.8) \\
\text { N } 120.5(0.8) \text { I }\end{array}$ & $\begin{array}{l}\text { I } 119.4(-1.6) \mathrm{N} 88.2(-1.8) \\
\text { S } 8.9(-22.6) \mathrm{K}\end{array}$ \\
\hline PEO5000- $b$-PMMAZO50 & 72 & 22.3 & 1.15 & 65.2 & 66.4 & $\begin{array}{l}\text { K 41.1(16.5) g } 77.8 \text { S } 93.0(2.1) \\
\text { N } 124.5(1.7) \mathrm{I}\end{array}$ & I $122.3(-2.0) \mathrm{N} 88.9(-2.1) \mathrm{S}$ \\
\hline PMMAZO & - & 25.3 & 1.10 & - & - & g 77.8 S $92.3(3.7) \mathrm{N} 133.3$ (3.1) I & I $131.6(-3.1) \mathrm{N} 89.4(-3.8) \mathrm{S}$ \\
\hline PEO2000 & - & 2.87 & 1.03 & - & - & K $54.5(182.9) \mathrm{I}$ & I $32.4(-179.1) \mathrm{K}$ \\
\hline PEO2000- $b$-PMMAZO10 & 64 & 7.4 & 1.12 & 54.6 & 61.1 & K $39.0(37.8)$ g 67.1 S $75.4(0.8)$ I & I $71.9(-1.5) \mathrm{K}$ \\
\hline PEO2000- $b$-PMMAZO20 & 66 & 10.5 & 1.08 & 66.9 & 72.7 & g 68.6 S $83.8(1.8) \mathrm{N} 100.7$ (1.6) I & I $99.5(-1.1) \mathrm{N} 80.4(-2.1) \mathrm{S}$ \\
\hline PEO2000- $b$-PMMAZO30 & 71 & 12.9 & 1.10 & 70.4 & 77.7 & g 66.5 S $86.9(2.0) \mathrm{N} 108.8$ (1.1) I & I $107.0(-1.3) \mathrm{N} 83.6(-2.3) \mathrm{S}$ \\
\hline PEO2000- $b$-PMMAZO40 & 60 & 15.1 & 1.10 & 73.5 & 81.0 & g 70.2 S $89.5(2.6) \mathrm{N} 114.6(1.5) \mathrm{I}$ & I $112.4(-1.5) \mathrm{N} 84.5(-2.6) \mathrm{S}$ \\
\hline PEO2000- $b$-PMMAZO50 & 67 & 17.7 & 1,11 & 74.3 & 83.8 & g 76.2 S 91.6(2.8) N $118.3(1.8) \mathrm{I}$ & I $116.0(-1.4) \mathrm{N} 86.2(-3.2) \mathrm{S}$ \\
\hline
\end{tabular}

${ }^{\mathrm{a}} \mathrm{S}=$ smectic phase, $\mathrm{N}=$ nematic phase, $\mathrm{g}=$ glassy phase, $\mathrm{K}=$ crystalline phase, $\mathrm{I}=$ isotropic.

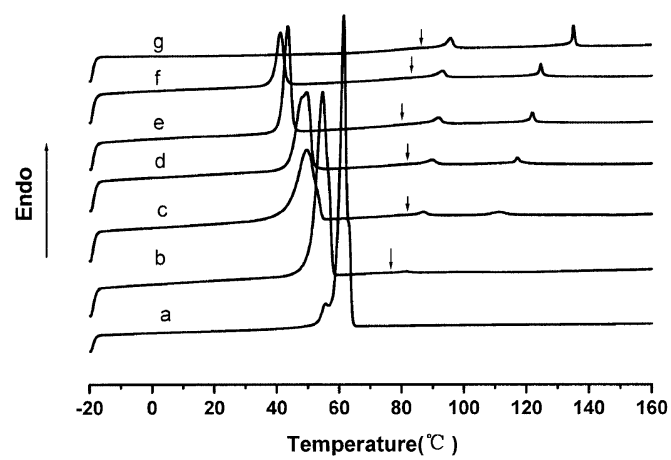

Figure 4. Second heating DSC spectra of PEO5000- $b$ PMMAZO: ${ }^{\mathrm{a}} \mathrm{PEO} 5000,{ }^{\mathrm{b}} \mathrm{PEO} 5000-b$-PMMAZO10, ${ }^{\mathrm{c}} \mathrm{PEO} 5000-$ $b$-PMMAZO20, $\quad{ }^{\mathrm{d}} \mathrm{PEO} 5000-b$-PMMAZO30, $\quad{ }^{\mathrm{e} P E O 5000-} b$ PMMAZO40, ${ }^{\mathrm{f}} \mathrm{PEO} 5000-b$-PMMAZO50, ${ }^{\mathrm{g}} \mathrm{PMMAZO}$. The arrow indicates the glass transition.

characterized by combination techniques consisting of differential scanning calorimetry (DSC), thermal polarized microscopy (POM). The transition temperatures and the corresponding enthalpy changes of all the samples obtained from the second heating and the first cooling scans are summarized in Table II. Figure 4 presents the DSC second heating traces of series of PEO5000- $b$-PMMAZO. PMMAZO is thermotropic liquid crystalline polymer, which exhibits a smectic phase and a nematic phase transition. ${ }^{16}$ To investigate the effect of liquid crystal block length, the liquid crystal block with a wide rang of molecular weights from $3.5 \times 10^{3}$ to $1.7 \times 10^{4}$ in every series was prepared. As can be observed from Figure 4 , the block copolymers PEO5000- $b$-PMMAZO

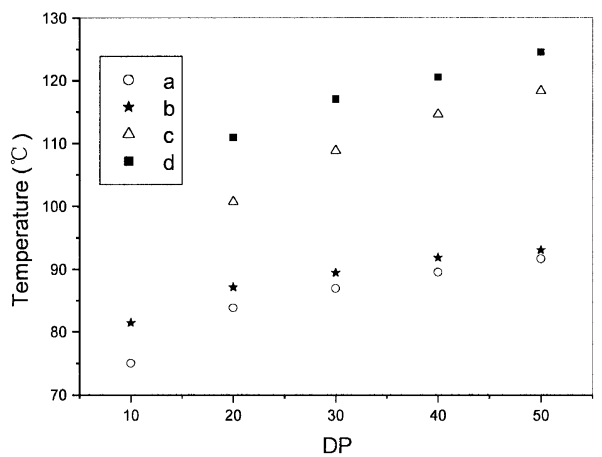

Figure 5. Dependence of phase transition temperatures on the theoretical degree of polymerization (DP) of PMMAZO liquid crystal block for the diblock copolymers: ${ }^{\mathrm{a}} T_{\mathrm{S}-\mathrm{N}}(\mathrm{PEO} 2000-$ $b$-PMMAZO), ${ }^{\mathrm{b}} T_{\mathrm{S}-\mathrm{N}}\left(\mathrm{PEO} 5000-b\right.$-PMMAZO), ${ }^{\mathrm{c}} T_{\mathrm{N}-\mathrm{I}}(\mathrm{PEO} 2000-b-$ PMMAZO), ${ }^{\mathrm{d}} T_{\mathrm{N}-\mathrm{I}}(\mathrm{PEO} 5000-b$-PMMAZO).

show three dominant peaks, which can be assigned to the crystalline phase $(\mathrm{K})$ transition, the smectic phase $(\mathrm{S})$-nematic phase $(\mathrm{N})$ transition and the nematic phase (N)-isotropic (I) phase transition on second heating except for PEO5000- $b$-PMMAZO10. PEO5000- $b$ PMMAZO10 exhibits the crystalline phase transition, the smectic phase-isotropic phase transition, which a nematic phase does not appear. The similarity can be observed in the block copolymer PEO2000$b$-PMMAZO10. The block copolymers PEO5000- $b$ PMMAZO10 and PEO2000- $b$-PMMAZO10 show the direct transition of a smectic to an isotropic melt, which is due to the lowest molecular weight liquid crystal block with approximately 10 repeat units of MMAZO. The glass transition temperatures can be also observed. 
Figure 5 shows the dependence of phase transition temperatures of the block copolymers determined by the second heating of DSC as a function of the theoretical degree of polymerization (DP) of the liquid crystal block. From the data of Figure 5 and Table II, it can be found that the S-N transition temperatures $\left(T_{\mathrm{S}-\mathrm{N}}\right)$ change from $81.4^{\circ} \mathrm{C}$ to $93.0^{\circ} \mathrm{C}$, the N-I transition temperatures $\left(T_{\mathrm{N}-\mathrm{I}}\right)$ change from $110.9^{\circ} \mathrm{C}$ to $124.5^{\circ} \mathrm{C}$ for the series of PEO5000- $b$-PMMAZO with increasing molecular weight of PMMAZO block, and $T_{\mathrm{S}-\mathrm{N}}$ change from $75.4^{\circ} \mathrm{C}$ to $91.6^{\circ} \mathrm{C}, T_{\mathrm{N}-\mathrm{I}}$ change from $100.7^{\circ} \mathrm{C}$ to $118.3^{\circ} \mathrm{C}$ for the series of PEO2000- $b$-PMMAZO with increasing molecular weight of PMMAZO block. That is to say, $T_{\mathrm{S}-\mathrm{N}}$ and $T_{\mathrm{N}-\mathrm{I}}$ are affected by the molecular weight of PMMAZO block, which improve with the increasing molecular weight of PMMAZO block. It is possible that the increase degree of polymerization of PMMAZO is beneficial to stabilizing the liquid crystal phase. The result is well established in side chain liquid crystal homopolymer. ${ }^{7 \mathrm{a}, 17}$ On the other hand, the melting temperatures of the crystal, $T_{\mathrm{K}}$, decrease from $59.0^{\circ} \mathrm{C}$ to $41.1^{\circ} \mathrm{C}$ and the corresponding enthalpy values decrease from $194.7 \mathrm{~J} \mathrm{~g}^{-1}$ to $16.5 \mathrm{~J} \mathrm{~g}^{-1}$ with increasing molecular weight of PMMAZO block for the series of PEO5000- $b$-PMMAZO. It is possible that increasing chain length of block PMMAZO inhibit the crystallinity of PEO block. Hence, the crystallizability of PEO-b-PMMAZO becomes poor (Figure 5).

To study the effect of the PEO length, the two series block copolymers were synthesized. By compared the series of PEO5000- $b$-PMMAZO with that of PEO2000- $b$-PMMAZO, it was found that $T_{\mathrm{S}-\mathrm{N}}$ of the series of PEO5000- $b$-PMMAZO were smaller than that of the series of PEO2000- $b$-PMMAZO and $T_{\mathrm{N}-\mathrm{I}}$ of the series of PEO5000- $b$-PMMAZO were smaller than that of the series of PEO2000- $b$-PMMAZO for the same theoretical degree of polymerization of PMMAZO block. That is to say, the effect of PEO2000 block to the transition temperatures is more than that of PEO5000. The result can be obtained obviously from Figure 5. The trend is dissimilar for rod-coil diblock copolymer. ${ }^{3 b, 3 \mathrm{~d}}$ Polarized optical microscopic observations of all samples are consistent with the results of DSC. Transition from an isotropic liquid can be seen by the rapid formation of schlieren texture, followed by a focal conic fan texture indicating a smectic phase. Spherulite can be seen with further cooling. Figure 6 is representative optical polarized micrograph.

\section{CONCLUSION}

Two series of novel side chain liquid crystal-coil (LC-coil) diblock copolymers with narrow molecular

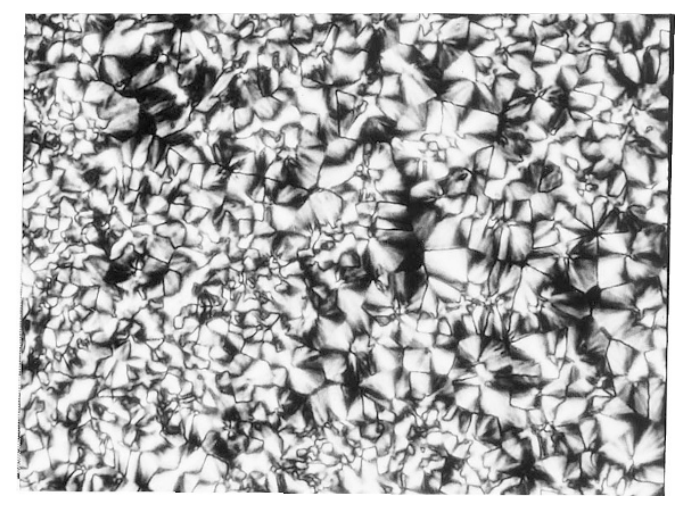

a

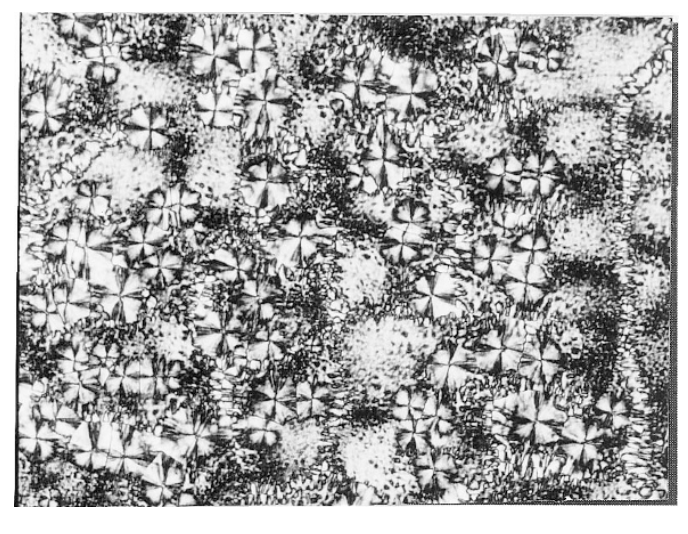

b

Figure 6. Representative polarized micrograph of the texture of PEO5000- $b$-PMMAZO30: ${ }^{\mathrm{a}} 85^{\circ} \mathrm{C}(400 \times)$; ${ }^{\mathrm{b}} 30^{\circ} \mathrm{C}(100 \times)$.

weight distributions were synthesized first successfully by ATRP. They were characterized by gel permeation chromatograph (GPC), proton nuclear magnetic resonance $\left({ }^{1} \mathrm{H}\right.$ NMR), Fourier transform infrared (FT-IR) spectra, differential scanning calorimetry (DSC) and polarized optical microscope (POM). It was observed that the block polymers exhibited a smectic and a nematic phase except for PEO5000- $b$-PMMAZO10 and PEO2000- $b$-PMMAZO10. The phase transition temperatures of $T_{\mathrm{S}-\mathrm{N}}$ and $T_{\mathrm{N}-\mathrm{I}}$ improved with increasing molecular weight of the LC block. The crystallizability of the PEO block of diblock copolymers depressed with increasing molecular weight of the LC block.

\section{REFERENCES}

1. B. Gallot, Prog. Polym. Sci., 21, 1035 (1996).

2. S. I. Stupp, V. LeBonheur, K. Walker, L. S. Li, K. E. Huggins, M. Keser, and A. Amstutz, Science, 276, 384 (1997).

3. a) M. Lee, B. K. Cho, and W. C. Zin, Chem Commun., 1787 (1996).

b) M. Lee, B.-K. Cho, H. Kim, J.-Y. Yoon, and W. C. Zin, J. Am. Chem. Soc., 120, 9168 (1998).

c) M. Lee, D. W. Lee, B.-K. Cho, J.-Y. Yoon, and W. C. Zin, J. Am. Chem. Soc., 120, 13258 (1998).

d) M. Lee and N. K. Oh, J. Mater. Chem., 6, 1079 (1996).

4. a) L. H. Radzilowski and S. I. Stupp, Macromolecules, 27, 
7749 (1994).

b) L. H. Radzilowski, B. O. Carragher, and S. I. Stupp, Macromolecules, 30, 2110 (1997).

5. J. T. Chen, E. L. Thomas, C. K. Ober, and S. S. Hwang, Macromolecules, 28, 1688 (1995).

6. X. H. Wan, Y. F. Tu, D. Zhang, and Q. F. Zhou, Polym. Int., 49, 243 (2000).

7. a) M. Yamada, T. Iguch, A. Hirao, S. Nakahama, and J. Watanabe, Macromolecules, 28, 50 (1995).

b) M. Yamada, T. Itoh, R. Nakagawa, A. Hirao, S. Nakahama, and J. Watanabe, Macromolecules, 32, 282 (1999).

(c) M. Yamada, T. Iguchi, A. Hirao, S. Nakahama, and J. Watanabe, Polym. J., 30, 23 (1998).

8. Z. Komiya and R. R. Schrock, Macromolecules, 26, 1387 (1993).

9. V. Percec and M. Lee, Pure, Appl. Chem., A29, 723 (1992).

10. a) G, P. Mao, J. G. Wang, S. R. Clingman, C. K. Ober, J. T. Chen, and E. L. Thomas, Macromolecules, 30, 2556 (1997). b) B. Zaschke, W. Frank, H. Fisher, K. Schmutzler, and M. Arnold, Polym. Bull., 27, 1 (1991).

c) H. Fischer, S. Poser, and M. Arnold, Macromolecules, 28,
6957 (1995).

d) H. Fischer, S. Poser, M. Arnold, and W. Frank, Macromolecules, 27, 7133 (1994).

e) J. Sänger and W. Gronski, Macromol. Chem. Phys., 199, 555 (1998).

11. a) A. Moment, R. Miranda, and P. T. Hanmond, Macromol. Rapid Commum., 19, 573 (1998).

b) W. Y. Zheng and P. T. Hammond, Macromol. Rapid Commun., 17, 813 (1996).

12. J. G. Wang, G. P. Mao, C. K. Ober, and E. J. Kramer, Macromolecules, 30, 1906 (1997).

13. Y. Kodera, A. Matsusthima, M. Hiroto, H. Nishimura, A. Ishii, T. Ueno, and Y. Inada, Prog. Polym. Sci., 23, 1233 (1998).

14. D. Stewart and C. T. Imrie, Polymer, 37, 3419 (1996).

15. K. Jankobva, X. Chen, J. Kops, and W. Batsberg, Macromolecules, 31, 538 (1998).

16. A. S. Angeloni, D. Caretti, C. Carlini, E. Chiellini, G. Galli, A. Altomare, R. Solaro, M. Laus, Liq. Cryst., 4, 513 (1989).

17. T. Sagane and R. W. Lenz, Polymer, 30, 2269 (1989). 